\title{
Sistem Informasi Pendaftaran Pasien Rawat Jalan Secara Online Menggunakan Metode Extreme Programming
}

\author{
Arief Rusman ${ }^{1}$, Kresna Ramanda ${ }^{2}$, Rizka Syaleha ${ }^{3}$ \\ 1, 2 Universitas Nusa Mandiri \\ e-mail : ${ }^{1}$ arief.aef@nusamandiri.ac.id, ${ }^{2}$ kresna.kra@nusamandiri.ac.id \\ 3 Universitas Bina Sarana Informatika \\ e-mail : rizkasya14@gmail.com
}

\begin{abstract}
Abstrak
Rumah Sakit Siaga Raya, merupakan salah satu Rumah Sakit yang bergerak dibidang pelayanan Orthopedi dan Traumatologi (Bedah Tulang) dipilih sebagai tempat studi kasus yang dinilai memiliki data dan informasi yang cukup lengkap dimana tugas dan fungsinya memberikan pelayanan kesehatan terhadap masyarakat dan Sistem Informasi Manajemen Rumah Sakit lebih khususnya dibidang pendaftaran pasien rawat jalan yang akan berobat. Dalam pelaksanaan Pendaftaran Pasien Rawat Jalan, sistem yang digunakan oleh Rumah Sakit Siaga Raya belum cukup memberikan kemudahan bagi Pasien tersebut Sebagai konsumen yang menerima pelayanan. Maka untuk mengatasi permasalahan tersebut, dilakukan pembuatan Sistem informasi pada pendaftaran pasien rawat jalan secara online menggunakan metode extreme programming, dengan tujuan membantu pihak rumah sakit dalam mengelolah data dan informasi pendaftaran pasien rawat jalan sehingga dapat mempermudah berjalannya pendaftaran pasien rawat jalan menjadi lebih efisien. Hasil akhir dari pembuatan Sistem informasi pada pendaftaran pasien rawat jalan secara online menggunakan metode extreme programming ialah suatu rancangan sistem informasi yang membantu pasien dalam melakukan pendaftaran dengan menggunakan teknologi pendukung.
\end{abstract}

Kata kunci : Rumah Sakit, Sistem Informasi, Extreme Programming, Pendaftaran Pasien Rawat Jalan

\begin{abstract}
Siaga Raya Hospital, which is one of the hospitals engaged in Orthopedic and Traumatology services (Bone Surgery) was chosen as a case study site which is considered to have sufficient data and information where its duties and functions are to provide health services to the public and Hospital Management Information Systems more specifically in the field of outpatient registration for treatment. In implementing outpatient registration, the system used by the Siaga Raya Hospital is not sufficient to provide convenience for these patients as consumers who receive services. So to overcome this problem, an information system was made on outpatient registration online using the extreme programming method, with the aim of helping the hospital in managing data and information on outpatient registration so that it can facilitate the running of outpatient registration to be more efficient. The final result of making an information system on outpatient registration online using the extreme programming method is an information system design that helps patients register using supporting technology.
\end{abstract}

Keywords : Hospitals, Information Systems, Extreme Programming, Outpatient Registration 


\section{Pendahuluan}

Rumah Sakit Siaga Raya, merupakan salah satu Rumah Sakit yang bergerak dibidang pelayanan Orthopedi dan Traumatologi (Bedah Tulang) dimana tugas dan fungsinya memberikan pelayanan kesehatan terhadap masyarakat, baik masyarakat sekitar maupun dari luar lingkungan Rumah Sakit. Salah satu faktor yang mempengaruhi kelancaran operasional dan kemajuan dalam suatu perusahaan atau instansi adalah pelayanan yang baik dengan sistem yang baik pula, maka dari itu sistem pengelolaan data pada pelayanan RS Siaga Raya pada saat ini telah menggunakan sistem yang telah terkomputerisasi. Pelayanan kesehatan yang bermutu adalah pelayanan kesehatan yang selalu berupaya memenuhi harapan pasien (Fuanasari, Suparwati, \& Wigati, 2014). Namun pada saat ini sistem pendaftaran/registrasi pada pasien masih dilakukan penginputan data di tempat (rumah sakit). Pelayanan pendaftaran ini merupakan pintu gerbang utama dari sarana pelayanan kesehatan karena dari sinilah seorang pasien akan memberikan penilaian pertama terhadap pelayanan yang didapatnya dari sebuah sarana pelayanan kesehatan (llyas, 2017). Dengan melihat adanya kendala ini maka diperlukan sistem yang dapat mempermudah kinerja kariyawan dalam pengelolaan data dan informasi sehingga meminimalisir banyak pasien yang akan berobat melakukan registrasi di tempat.

\section{Metode Penelitian}

2.1. UML (Unified Modelling Language)

UML adalah Keluarga notasi grafis yang didukung oleh meta-model tunggal, yang membantu pendeskripsian dan desain sistem perangkat lunak khususnya sistem yang dibangun menggunakan pemrograman berorientasi objek (Fowler, 2005).

\subsection{ERD (Entity Relationship Diagram)}

ERD adalah bentuk paling awal dalam melakukan perancangan basis data relasional. ERD merupakan singkatan dari Entity Relationship Diagram, dikembangkan berdasarkan teori himpunan dalam bidang matematika. ERD digunakan untuk pemodelan basis data relasional. Sehingga jika penyimpanan basis data menggunakan OODBMS (Object Oriented Database Management System) maka perancangan basis data tidak perlu menggunakan ERD. Model ERD terdiri dari beberapa komponen dasar yaitu Entitas, Atribut, Relasi dan Tingkat Hubungan (Sukamto \& Shalahuddin, 2013).

\subsection{Pengertian Sistem}

Sistem adalah kumpulan dari elemenelemen yang berinteraksi untuk mencapai suatu tujuan tertentu(Mustakini, 2005). Pendekatan sistem yang merupakan jaringan kerja dari prosedur yang lebih menekankan urutan-urutan operasi. Suatu prosedur adalah suatu urutan-urutan yang tepat dari tahapan-tahapan instruksi yang menerangkan apa (what) yang harus dikerjakan, siapa (who) yang mengerjakan, kapan (when) dikerjakan dan bagaimana (how) mengerjakannya. Suatu sistem mempunyai karakteristik atau sifat-sifat tertentu (Ladjamudin, 2013)

\subsection{Pengertian Informasi \\ Informasi adalah data yang telah diklasifikasikan atau diolah atau} diinterpretasikan untuk digunakan dalam proses pengambilan keputusan (Sutabri, 2012)

\subsection{Pengertian Sistem Informasi}

Sistem informasi adalah suatu sistem didalam suatu organisasi yang mempertemukan kebutuhan pengolahan transaksi harian yang mendukung fungsi operasi organisasi yang bersifat manajerial dengan kegiatan strategi dari suatu organisasi untuk dapat menyediakan kepada pihak luar tertentu dengan laporan-laporan yang diperlukan (Ferdiana, 2012). Sistem informasi merupakan komponen yang terdiri dari manusia, teknologi informasi, prosedur kerja yang memproses, menyimpan, menganalisa, menyebarkan informasi untuk mencapai (Kurniawati \& Ghofar, 2017).

\subsection{Extreme Programming}

Extreme Programming dikenal dengan metode technical how to atau bagaimana suatu tim teknis mengembangkan perangkat lunak secara efisien melalui berbagai prinsip dan teknik praktis pengembangan perangkat lunak. XP menjadi dasar bagaimana tim bekerja sehari-hari (Fowler, 2005). 


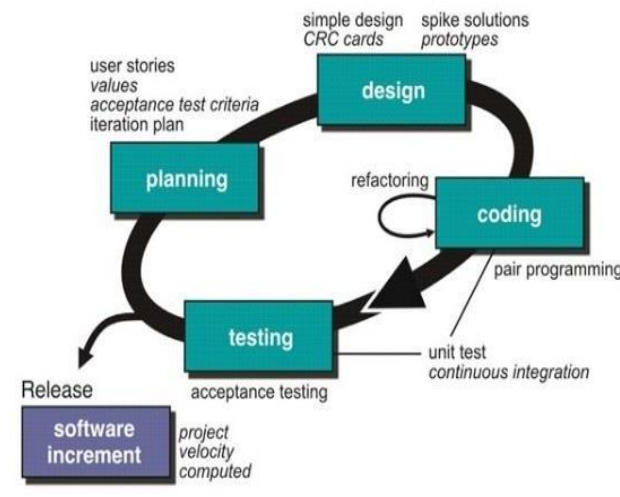

Sumber : (Fowler, 2005)

Gambar 1. Tahapan penelitian model Extreme Programming

\section{a. Tahap Planning}

Planning yaitu Tahap planning dimulai dengan membuat user stories yang menggambarkan output, fitur, dan fungsifungsi dari software yang akan dibuat. User stories tersebut kemudian diberikan bobot seperti prioritas dan dikelompokkan untuk selanjutnya dilakukan proses delivery secara incremental.

\section{b. Tahap Design}

Design pada Extreme Programming mengikuti prinsip Keep It Simple (KIS). Untuk design yang sulit, Extreme Programming akan menggunaan Spike Solution dimana pembuatan design dibuat langsung ke tujuannya. Extreme Programming juga mendukung adanya refactoring dimana software system diubah sedemikian rupa dengan cara mengubah stuktur kode dan menyederhanakannya namun hasil dari kode tidak berubah.

\section{c. Tahap Coding}

Proses coding pada XP diawali dengan membangun serangkaian unit test. Setelah itu pengembang akan berfokus untuk mengimplementasikannya. Dalam Extreme Programming diperkenalkan istilah Pair Programming dimana proses penulisan program dilakukan secara berpasangan. Dua orang programmer saling bekerjasama di satu komputer untuk menulis program. Dengan melakukan ini akan didapat real-time problem solving dan real- time quality assurance.

\section{d. Tahap Testing}

Tahap ini dilakukan pengujian kode pada unit test. Dalam Extreme Programming, diperkenalkan XP acceptance test atau biasa disebut customer test. Tes ini dilakukan oleh customer yang berfokus kepada fitur dan fungsi sistem secara keseluruhan. Acceptance test ini berasal dari user stories yang telah diimplementasikan.

\section{Hasil dan Pembahasan}

\subsection{Tahap Planning}

Pada tahapan planning, direkap kebutuhan dari sistem yang akan dibuat seperti pasien dapat melihat jadwal dokter dan dapat melakukan pendaftaran. Bagian administrasi daapt melihat data pasien, data obat, data dokter, data rekam medis pasien.

\subsection{Tahap Design}

a. Usecase Diagram

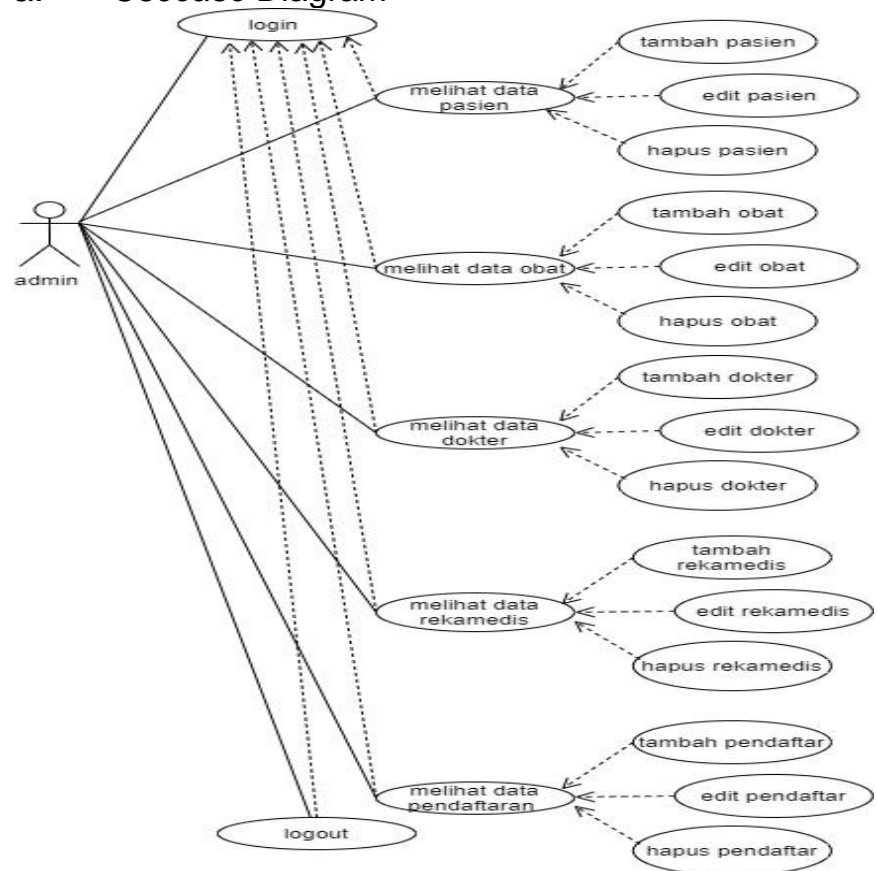

Sumber : Hasil Penelitian (2020)

Gambar 2. Usecase Diagram Admin

b. Entity Relationship Diagram (ERD)

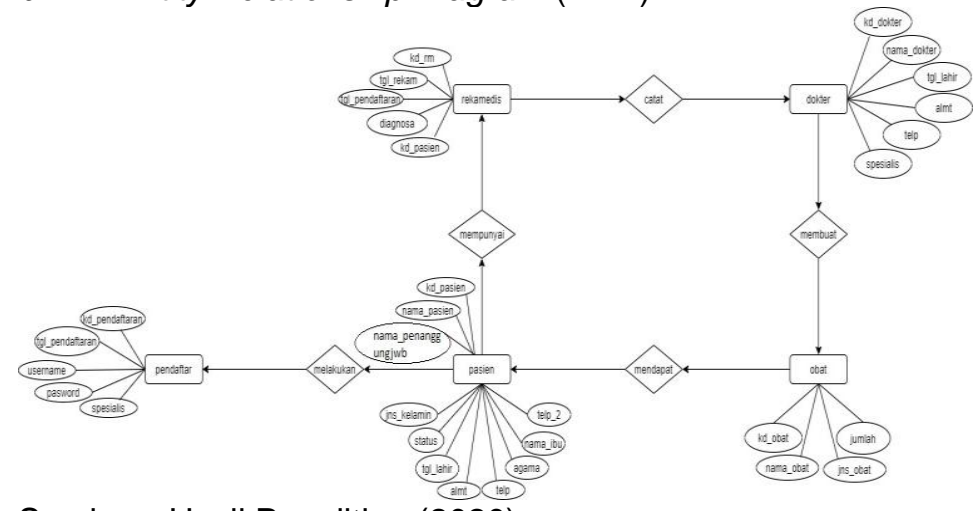

Sumber : Hasil Penelitian (2020)

Gambar 3. Entity Relationship Diagram

(ERD) Pendaftaran Pasien Rawat Jalan 
c. Logical Record Structure (LRS)

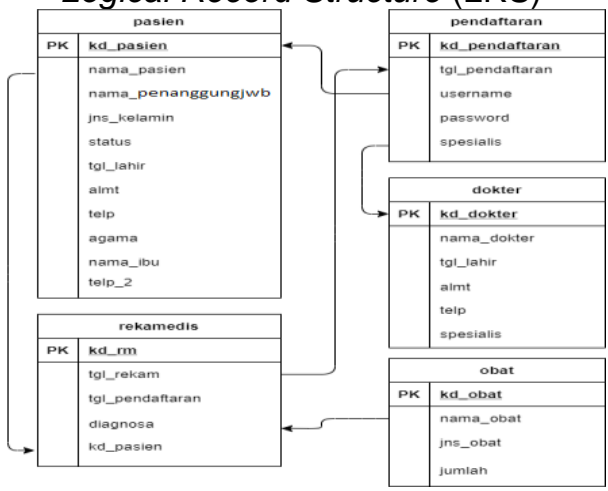

Sumber : Hasil Penelitian (2020)

Gambar 4. Logical Record Structure (LRS)

Pendaftaran Pasien Rawat Jalan

d. Class Diagram

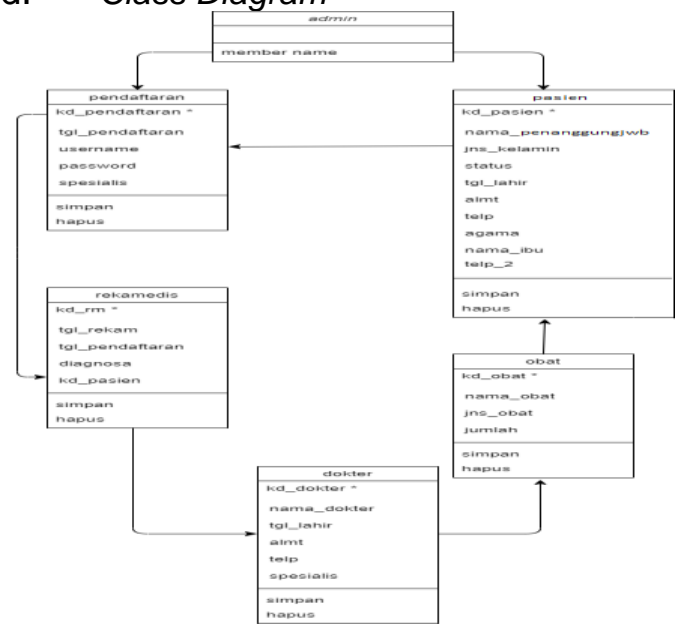

Sumber :

Gambar 5. Class Diagram Pendaftaran Pasien Rawat Jalan

e. Sequence Diagram

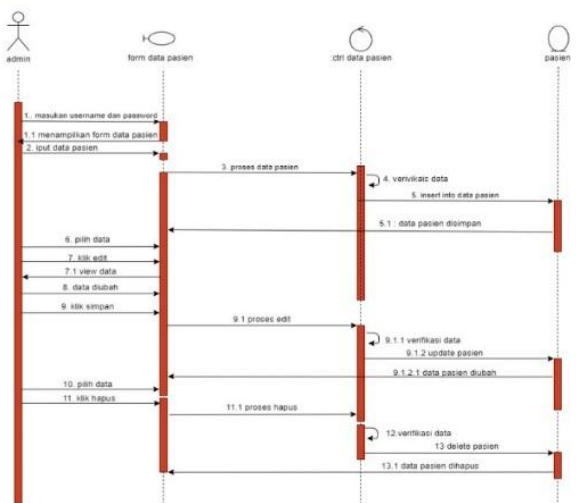

Sumber : Hasil Penelitian (2020)

Gambar 6. Sequence Diagram Menu Daftar Pasien

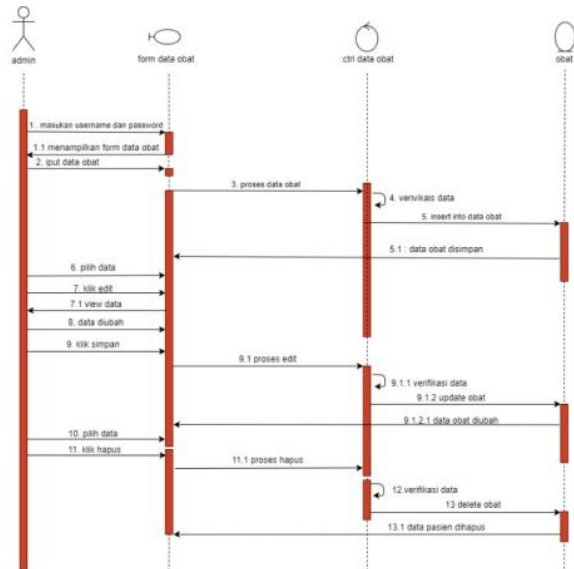

Sumber : Hasil Penelitian (2020)

Gambar 7. Sequence Diagram Menu Daftar Obat

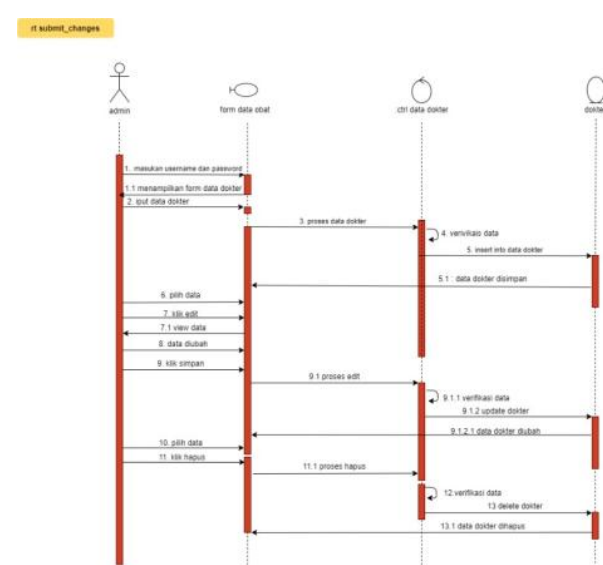

Sumber : Hasil Penelitian (2020)

Gambar 8. Sequence Diagram Menu Daftar Dokter

insome conopest

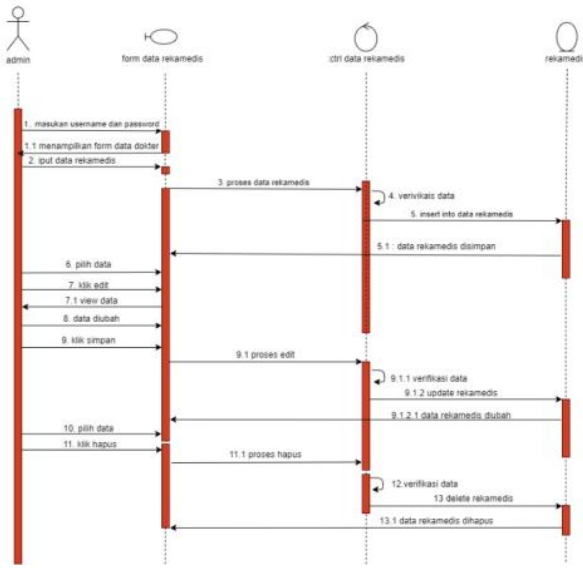

Sumber : Hasil Penelitian (2020)

Gambar 9. Sequence Diagram Menu Daftar Rekam Medis 
insubmitchanges

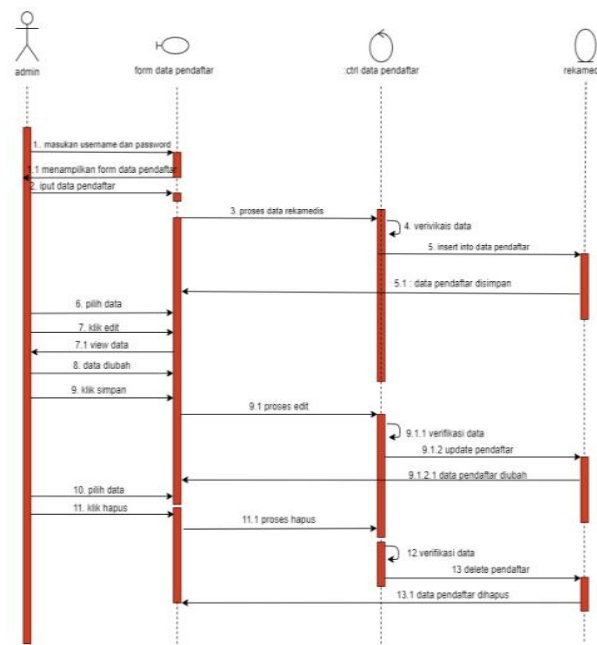

Sumber : Hasil Penelitian (2020)

Gambar 10. Sequence Diagram Menu Pendaftar

\subsection{Tahap Coding}

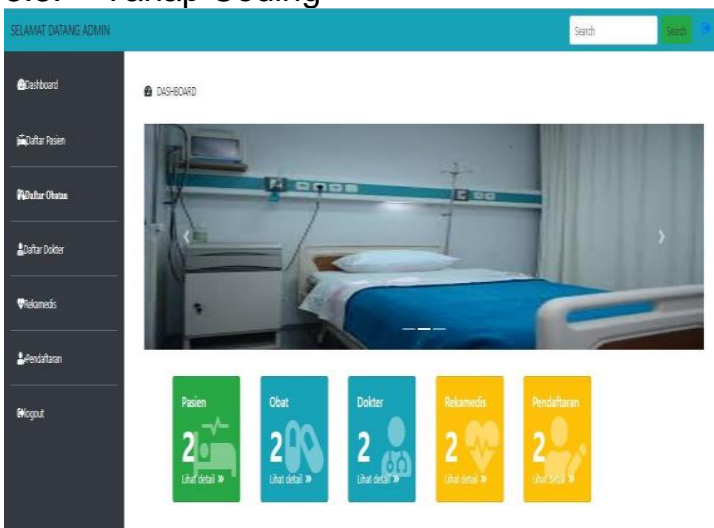

Sumber : Hasil Penelitian (2020)

Gambar 11. Tampilan Beranda Administrator

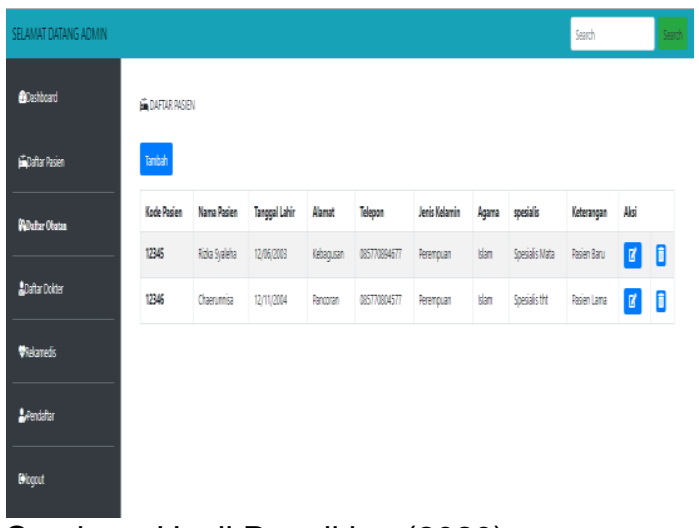

Sumber : Hasil Penelitian (2020)

Gambar 12. Tampilan Data Pasien

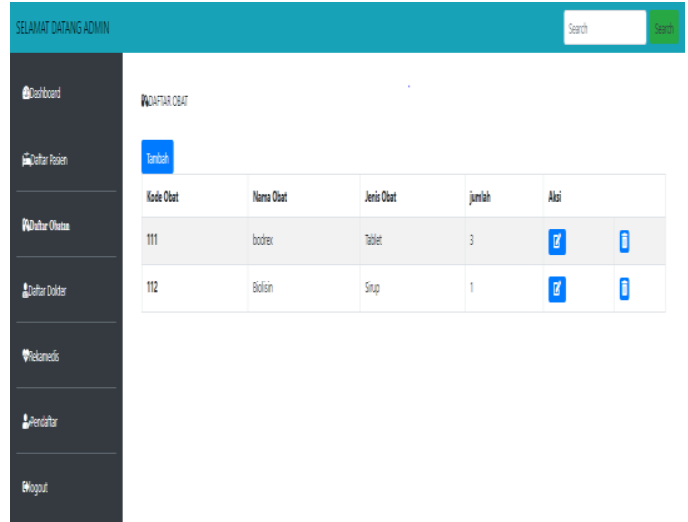

Sumber : Hasil Penelitian (2020) Gambar 13. Tampilan Data Obat
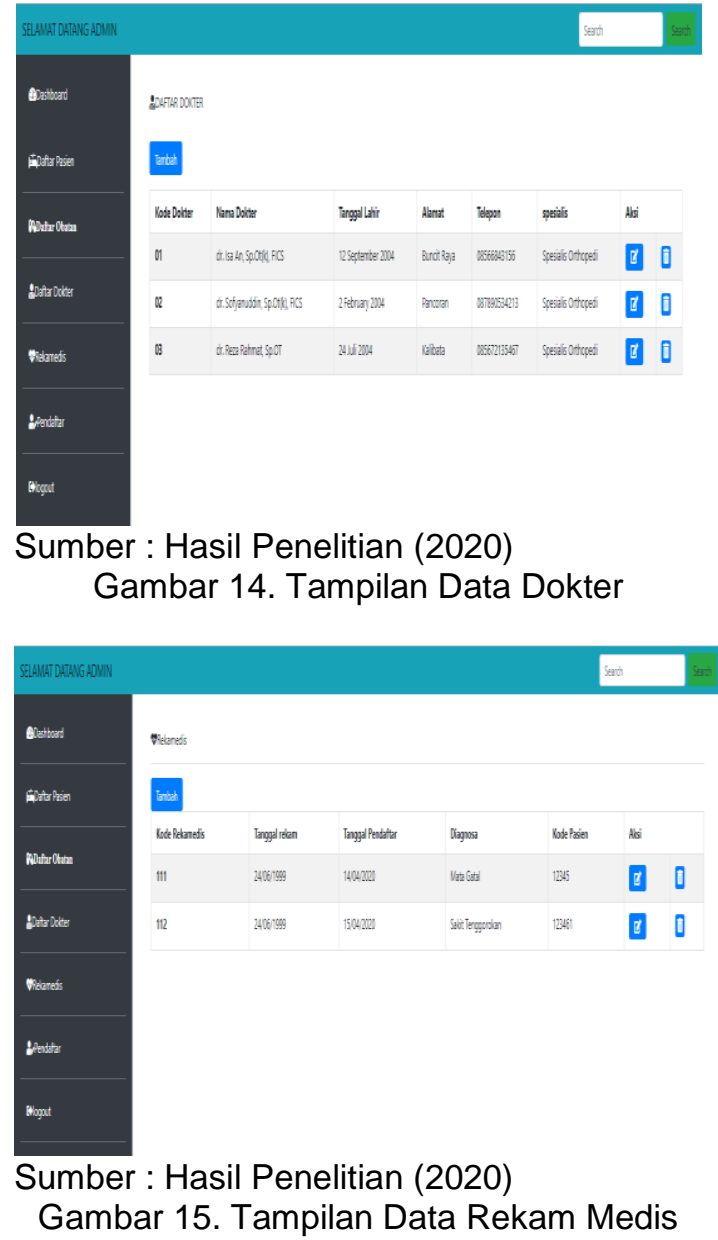

\subsection{Tahap Testing}

Teknik pengujian blackbox berfokus pada domain informasi dari perangkat lunak menggunakan test case dengan cara mempartisi domain input dari suatu program dengan cara memberikan cakupan pengujian yang mendalam. Dari serangkaian uji coba didapatkan hasil yang cukup baik. Semua fungsi menu berjalan dengan tepat sesuai dengan perancangan. Secara keseluruhan 
sistem ini sudah layak di uji cobakan kepada user.

Tabel 1. Hasil Pengujian Halaman Login Admin

\begin{tabular}{|c|c|c|c|c|}
\hline No & $\begin{array}{l}\text { Skenario } \\
\text { Pengujian }\end{array}$ & Test Case & $\begin{array}{l}\text { Hasil yang } \\
\text { diharapkan }\end{array}$ & $\begin{array}{r}\text { Hasil } \\
\text { Pengujian }\end{array}$ \\
\hline 1 & $\begin{array}{l}\text { Mengosongkan } \\
\text { semua isian } \\
\text { data login pada } \\
\text { login admin, } \\
\text { lalu langsung } \\
\text { klik tombol } \\
\text { "Login". }\end{array}$ & $\begin{array}{c}\text { Username } \\
\text { : (kosong) } \\
\text { Password } \\
\text { : } \\
\text { (kosong) }\end{array}$ & $\begin{array}{l}\text { Sistem akan } \\
\text { memproses } \\
\text { akses login } \\
\text { dan akan } \\
\text { menampilkan } \\
\text { messagebox } \\
\text { “Username: } \\
\text { dan } \\
\text { Password: } \\
\text { yang anda } \\
\text { masukkan } \\
\text { tidak } \\
\text { terdeteksi } \\
\text { oleh sistem” }\end{array}$ & $\begin{array}{l}\text { Sesuai } \\
\text { harapan }\end{array}$ \\
\hline 2 & $\begin{array}{l}\text { Hanya mengisi } \\
\text { usename dan } \\
\text { mengosongkan } \\
\text { password, lalu } \\
\text { klik tombol } \\
\text { "Login". }\end{array}$ & $\begin{array}{l}\text { Username } \\
\text { : Admin } \\
\text { Password } \\
: \text { (kosong) }\end{array}$ & $\begin{array}{l}\text { Sistem akan } \\
\text { memproses } \\
\text { akses login } \\
\text { dan akan } \\
\text { menampilkan } \\
\text { messagebox } \\
\text { “Username: } \\
\text { Admin dan } \\
\text { Password: } \\
\text { yang anda } \\
\text { masukkan } \\
\text { tidak } \\
\text { terdeteksi } \\
\text { oleh sistem” }\end{array}$ & $\begin{array}{l}\text { Sesuai } \\
\text { harapan }\end{array}$ \\
\hline 3 & $\begin{array}{c}\text { Mengisi } \\
\text { username } \\
\text { dengan benar }\end{array}$ & $\begin{array}{c}\text { Username } \\
: \\
\text { Admin }\end{array}$ & $\begin{array}{l}\text { Sistem akan } \\
\text { memproses } \\
\text { akses login }\end{array}$ & $\begin{array}{l}\text { Sesuai } \\
\text { harapan }\end{array}$ \\
\hline
\end{tabular}

dan password yang kurang,

lalu klik tombol

"Login".

Password

P

dan akan

(admn)

menampilkan

messagebox

"Username:

Admin dan

Password:

admn, yang

anda

masukkan

tidak

terdeteksi

oleh sistem"

Mengisi data

login yang

benar, lalu klik

tombol "Login".

Admin

memproses

.

akses login ,

:

akan

Admin

menampilkan

messagebox

"Anda Login

Dengan

Admin " dan

akan masuk

ke halaman

admin

Sumber : Hasil Penelitian (2020)

Tabel 2. Hasil Pengujian Halaman Input

$$
\text { Data Dokter }
$$

\begin{tabular}{|c|c|c|c|c|}
\hline No & Skenario & Test Case & Hasil yang & Hasil \\
& Pengujian & & diharapkan & Pengujian \\
\hline 1 & Mengosongkan & Kode Dokter: & Sistem akan & Sesuai \\
& kode dokter, & (kosong) & menampilkan & harapan \\
& nama dokter, & Nama & messagebox & \\
& tanggal lahir, & Dokter: & "Anda yakin & \\
alamat, telepon & (kosong) & ingin & \\
& dan spesialis & Tanggal lahir: & menyimpan & \\
& pada entry & & data?". Jika & \\
\hline
\end{tabular}




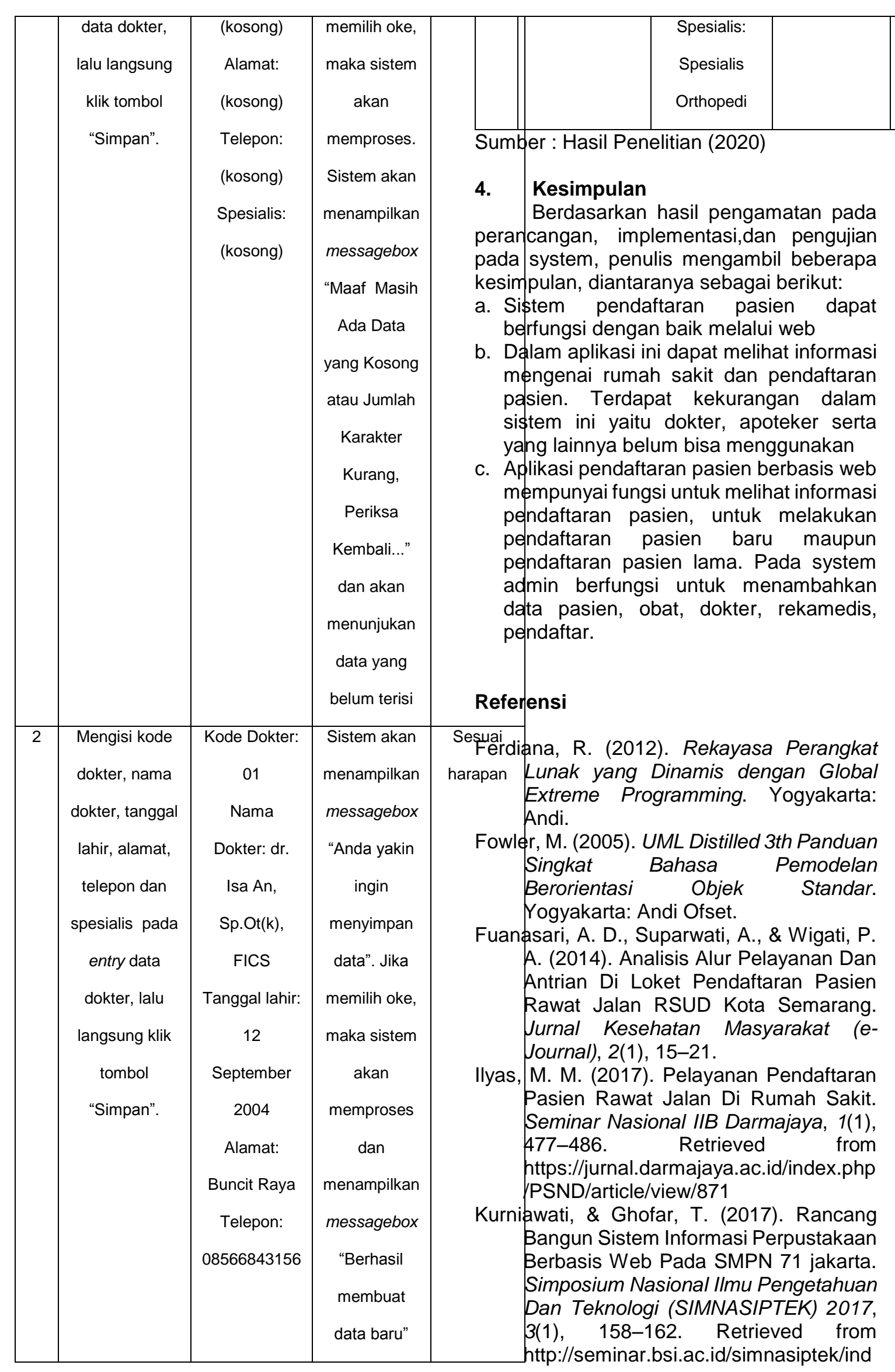


ex.php/simnasiptek-

2017/article/view/135

Ladjamudin, A.-B. (2013). Analisis dan

Desain Sistem Informasi. Yogyakarta: Graha IImu.

Mustakini, J. H. (2005). Analisis \& Desain Sistem Informasi. Yogyakarta: Andi.
Sukamto, R. A., \& Shalahuddin, M. (2013). Rekayasa perangkat lunak terstruktur dan berorientasi objek. Bandung: Informatika.

Sutabri, T. (2012). Analisa Sistem Informasi. Yogyakarta: Andi. 